\title{
Cover separation of CFRP strengthened beam-type cantilevers with steel bolt anchorage
}

DOI:

10.1016/j.engstruct.2017.10.056

\section{Document Version}

Accepted author manuscript

Link to publication record in Manchester Research Explorer

\section{Citation for published version (APA):}

Zhang, D., Shi, H., Zhu, J., Su, M., \& Jin, W. L. (2018). Cover separation of CFRP strengthened beam-type cantilevers with steel bolt anchorage. Engineering Structures, 156, 224-234.

https://doi.org/10.1016/j.engstruct.2017.10.056

\section{Published in:}

Engineering Structures

\section{Citing this paper}

Please note that where the full-text provided on Manchester Research Explorer is the Author Accepted Manuscript or Proof version this may differ from the final Published version. If citing, it is advised that you check and use the publisher's definitive version.

\section{General rights}

Copyright and moral rights for the publications made accessible in the Research Explorer are retained by the authors and/or other copyright owners and it is a condition of accessing publications that users recognise and abide by the legal requirements associated with these rights.

\section{Takedown policy}

If you believe that this document breaches copyright please refer to the University of Manchester's Takedown Procedures [http://man.ac.uk/04Y6Bo] or contact uml.scholarlycommunications@manchester.ac.uk providing relevant details, so we can investigate your claim.

\section{OPEN ACCESS}




\section{Cover Separation of CFRP Strengthened Beam-type cantilevers with steel bolt anchorage}

Dawei Zhang ${ }^{1}$, Haifeng Shi ${ }^{1}$, Jihua $\mathrm{Zhu}^{2 *}$, Meini Su${ }^{3 *}$ and W.L.Jin ${ }^{1}$

${ }^{1}$ Institute of Structural Engineering, ZheJiang University, 310058 Hangzhou, Zhejiang, China. ${ }^{2}$ Guangdong Province Key Laboratory of Durability for Marine Civil Engineering, School of Civil Engineering, Shenzhen University, Shenzhen, Guangdong, China.

${ }^{3}$ School of Mechanical, Aerospace and Civil Engineering, University of Manchester, Manchester. UK. *Corresponding author (Jihua Zhu). Email address: zhujh@szu.edu.cn

\section{Abstract}

*Corresponding author (Meini Su). Email address: meini.su@manchester.ac.uk

Concrete cover separation is one of the premature debonding failure modes commonly observed when strengthening reinforced concrete (RC) beams that use externally bonded fibre-reinforced polymer (EB-FRP) become delaminated. Anchorage systems, which postpone or prevent debonding, have proven to be an effective method to achieve higher levels of FRP utilization. Although researchers have widely acknowledged the efficiency of anchorage systems, the effect of a bottom steel bolt anchorage system on the concrete cover separation strength remains unclear. The related design formulation is still in its initial stage, which limits the practical use of this type of anchorage system for FRP strengthening. In this study, specimens of carbon fibrereinforced polymer (CFRP) laminate strengthened beam-type cantilevers with bottom steel bolt anchors were designed and tested. The principle design parameters such as the location, the length and the number of anchors were investigated and their effects were discussed based on the test results. Furthermore, an analytical approach considering various failure modes of anchors and cantilevers was presented to predict the concrete cover separation strength of anchored specimens. The test results were then compared to the analytical approach in order to verify reliability and accuracy.

Keywords: CFRP laminate, concrete tooth, cantilever, steel bolt anchorage, concrete cover separation

\section{Introduction}

Over the last decades, external bonding of fibre-reinforced polymer (EB-FRP) to reinforced concrete (RC) members has been widely used in the rehabilitation practice of deficient concrete structures. Experiments have comprehensively shown this strengthening method to be an effective and convenient way to improve static and fatigue performance of RC structures under service loads, and to increase their ultimate strength [1-3]. This rehabilitation method has attracted researchers' interest worldwide because of its superior advantage in resistance to corrosion, increased durability, flexibility and a high stiffness-to-weight ratio compared to using steel plates. 
Despite promising developments in the implementation of FRP for the repair and retrofit of RC structures, previous literature has shown that the application of FRP composites can lead to brittle failure when the FRP composite debonds before reaching design strength [4-5]. The bond deterioration caused by the single or coupled impact of environment (moisture, temperature, chloride ions, etc.), load (sustained load, fatigue, etc.) and the existence of defects at the FRP/concrete interface even made the problem more critical [6-9]. Among premature debonding failure modes, concrete cover separation failure is often observed. This failure mode initiates at the critical plate end then propagates along the level of substrate tension reinforcement toward the beam's mid-span [10-13]. Three general topics are used to explain the concrete cover separation of a strengthened beam [14]: (1) the derivation of elastic stress concentration at the FRP end, (2) the strengthened beams' shear capacity and (3) the concrete tooth model, which was firstly proposed by Raoof and Hassanen $[15,16]$ and the concrete cover separation was regarded as the failure of a cantilever formed between two adjacent cracks.

Standards and design guidelines impose limits on the maximum strain level of the composite material that may be utilized in design in order to prevent this type of failure [17]. Sallam et al. [18] proved that concrete cover replacement technique, which replaced the concrete cover with grout layer before strengthening, can efficiently prevent the concrete cover separation. Existing studies on steel plate or FRP laminate strengthening have shown that the application of anchoring systems is also an effective way to mitigate and suppress debonding failures to enhance the efficiency of utilization of the FRP material. To date, various anchorage measures have been investigated including [17]: (1) Mechanically fastened metallic anchors [19-22], (2) Ujacket anchors [23-26] and (3) FRP anchors [27-30]. Metallic anchorages with a steel bolt anchorage system were one of the first types of FRP end anchorage devices investigated [31]. Researchers such as Garden and Hollaway [19], Duthinh and Starnes [21] and Maaddawy and Soudki [32] have discovered that the use of metallic anchorages provides a significant increase in anchorage strength, as well as ductility enhancement. Although FRP anchor has its advantage over conventional steel anchor especially due to its high corrosion resistance, steel anchor still shows its practical importance in easy and well developed installation technique, relative lower cost and induce of compressive stress acting on the interface to enhance the bond strength of FRP/concrete interface by tightening steel nut with torque wrench [18]. Stainless steel anchor is also one of options for corrosive environment.

Steel bolt anchorage combined with EB-FRP is also called a hybrid-bonding FRP system (HB-FRP) in some literature [32-36]. Wu and Huang [33] installed steel nails as anchorage along the bonded FRP strip's 
length to produce greater resistance to the separation of the FRP strip from the concrete substrate. Results showed that the interfacial bonding strength in HB-FRP strengthened members was 7.5 times of the bonding strength in EB-FRP strengthened members. Zhang et al. [35] conducted a total of 17 beam-shear experiments with mid-span pre-cutting fissures, and proposed formulas for calculating the debonding stress induced by intermediate cracks of EB-FRP and HB-FRP strengthened beams. Wu et al. [36] developed an improved hybrid bonded FRP (IHB-FRP) technique by applying a given pre-tightening force to the steel bolts, and found a more uniform strain distribution in the FRP strip in specimens with anchorage.

Despite extensive research efforts to study the effectiveness of steel bolt anchorage systems and to develop pre-stressed anchorage systems [36] and a bonding strength model [37], the study results are still far away from practical use. Parameters such as the location, the height and the spacing of steel bolts in the previous experiments were random, and didn't have a unified design code. Most of the previous studies focused on the effect of the anchorage system on the interfacial delamination of the FRP-concrete interface, through either bond shear testing with a given bond length or member testing with various anchorage arrangements [38-41]. There is still a lack of specially designed testing to clarify the mechanism of concrete cover separation and the anchorage system. In most of the available experiments in which concrete cover separation was observed, the location of cracks that formed the concrete teeth was not pre-determined. Thus the effect of the geometry of the concrete teeth and location of anchorages remained unclear, and the measurement of FRP strain exactly at the cracked section was difficult. In fact, FRP design guidelines stipulate that the practical implementation of anchorage devices should be substantiated by representative experimental testing (ACI 2008) [42]. Therefore, further efforts are necessary to reach a thorough understanding of the effect of anchorage systems, from which a reliable design could be proposed.

The authors are conducting a series of studies aiming at the development of an analytical approach for flexural strengthening of an existing structure with external FRP composites with various anchorage systems. The present work concentrates specifically on the use of a steel bolt anchorage system and its influence on the concrete cover separation of CFRP-strengthened specimens. Beam-type cantilever tests were designed with predetermined geometry of concrete teeth (cantilever) and the location of anchorage system. Thus the measurement of FRP strain exactly at the cracked section through the read of strain gages became possible, making the verification of the strength model easier and more reliable. The behaviors of CFRP strengthened specimens with and without bolted anchorage are experimentally and analytically investigated. An analytical model is developed 
to predict the response of CFRP-strengthened specimens with bolted anchorage. The reliability and accuracy of the proposed analytical procedure are then verified by comparing the analytical and experimental debonding load of the CFRP-strengthened cantilevers provided in this paper.

\section{Experiment program}

\subsection{Testing specimens}

The geometry and reinforcement arrangement of the RC members are shown in Fig. 1. The cross-section of the RC beam-type cantilever specimens is $120 \mathrm{~mm} \times 150 \mathrm{~mm}$, and the length is $600 \mathrm{~mm}$. All specimens had a clear span of $400 \mathrm{~mm}$, and employed two deformed bars of diameter $10 \mathrm{~mm}$ as respective compression and tension reinforcement. $10 \mathrm{~mm}$ diameter plain bar stirrups spaced at $100 \mathrm{~mm}$ were placed along the entire length of the beam. The thickness of concrete cover at bottom was $25 \mathrm{~mm}$, and $15 \mathrm{~mm}$ for both the side and top. The beam-type cantilever sections were formed between two adjacent $10 \mathrm{~mm}$ wide artificial cracks up to the level of tension reinforcement. CFRP U-anchors with height of $120 \mathrm{~mm}$ and width of $200 \mathrm{~mm}$ were used in another side to guarantee the targeted failure mode.

As shown in Table $1, l_{a}, d_{a}, n_{t}$ represents the length, the horizontal distance of steel bolt center to the right edge of inner artificial crack (or compression end of cantilever) and the number of steel bolt anchors, respectively. Specimens were divided into four groups, namely La to Ld, in which Lc was the only group anchored with two steel bolts (Fig. 1.c, $n_{t}=2$ ) of same length $l_{a}$ but different distances $d_{a}$, and Ld was the control group with no anchorage. Each series contains two identical specimens. Each specimen was assigned a name that consists of two letters and two numbers, e.g. La-50-1. The acronym designation adopted was as follows: the first letter L designates beams, the following letter represents the group series, the first number appearing after that corresponds to the steel bolt anchorage length, and the last number indicates series of specimens with the same parameters.

\subsection{Materials}

The mean value of cubic compressive strength $\left(f_{c u}\right)$ of three $150 \mathrm{~mm}$ concrete cubes was $31.27 \mathrm{MPa}$ after 28 days of curing. The modulus of elasticity $(E)$, yield strength $\left(f_{y}\right)$ and ultimate strength $\left(f_{u}\right)$ of deformed bars are 204.40 GPa, 463.0 MPa and 575.5 MPa, respectively, and 204.85 GPa, 342.5 MPa, 499.5 MPa, respectively for plain bars, based on respective uniaxial tension tests. The diameter, modulus of elasticity and ultimate strength of steel bolts are $10 \mathrm{~mm}, 152.80 \mathrm{GPa}, 824.0 \mathrm{MPa}$, respectively, as provided by the manufacturer. 
Two strips of CFRP laminates were attached to the bottom surface of the cantilever specimens. Each strip of CFRP laminate consisted of three layers of unidirectional textile. Each layer had a width of $40 \mathrm{~mm}$, length of $330 \mathrm{~mm}$ and a dry fibre thickness of $0.111 \mathrm{~mm}$. The elastic modulus and tensile strength of the CFRP laminate were $241 \mathrm{GPa}$ and $3696 \mathrm{MPa}$, respectively. Adhesive used for both CFRP laminate bonding and steel bolt anchorage bonding was a thixotropic epoxy resin with elastic modulus and tensile strength being equal to 2.83 $\mathrm{GPa}$ and $52 \mathrm{MPa}$, respectively.

\subsection{Specimen preparation}

The following procedure was adopted for specimen preparation. Artificial cracks of $10 \mathrm{~mm}$ wide and of height up to the centroid of tension reinforcement were made by two wood plates at casting to form a cantilever on one side of the specimens. Special attention was paid to ensure that one stirrup was placed above the center of cantilever section. The steel bolt system was furnished by preset holes using PVC tube with a diameter of $20 \mathrm{~mm}$. All specimens were extracted from the molds 24 hours after casting and then cured for 28 days. CFRP laminates were then bonded to the bottom surface of the specimens in a wet-layup procedure after sandblasting, brushing and cleaning of the concrete surface, which was done to guarantee an ideal bond between the CFRP laminate and the concrete. One layer of CFRP U-anchorage with a height of $120 \mathrm{~mm}$ and a width of $200 \mathrm{~mm}$ was then bonded to the non-cantilever side of the concrete beam in a similar procedure to avoid unexpected failure before the failure of the cantilever. FRP fiber direction was indicated by dashed lines in Fig. 1.b and 1.c. Steel bolts of different lengths were inserted into the preset holes, followed by pouring in epoxy resin to form a bond between the concrete and steel bolts. One or two $5 \mathrm{~mm}$ thick, $30 \mathrm{~mm}$ wide steel plate was pressed on the CFRP laminate with steel nuts, as indicated in Fig. 1.b or Fig. 1.c. All the specimens were then placed in a room-temperature environment for seven days for the adhesive curing before testing.

\subsection{Testing apparatus}

Three-point bending tests were carried out on all specimens with a shear span of $200 \mathrm{~mm}$ as indicated in Fig. 2. Two strain gauges were glued to the CFRP laminate (Fig. 1) to measure its strain response. As shown in Fig. 2, six strain gauges were attached to the tension steel bars with three strain gauges to each bar: one at each top of the two artificial cracks and one in the middle of the two artificial cracks. Two strain gauges were located at the middle of the stirrup above the cantilever section. The number "2" in the brackets of Fig. 2 refers to the label designation of strain gauge on the opposite side. The deflection was measured by means of LVDTs placed at the 
loading point and supports of the specimens, respectively. Specimens were tested monotonically until failure by a load controlled hydraulic jack at a constant loading rate of $2 \mathrm{kN} / \mathrm{min}$.

\section{Results and discussions}

\subsection{Failure mode}

As indicated in Fig. 3, two types of failure modes were observed for all specimens: flexural failure of the beam with (Mode I) and without (Mode II) full cantilever separation. During the loading procedure, the load was maintained at different load levels to record the crack distribution and the crack tips were marked with careful observation. The numbers with short solid line linking to the cracks in Fig. 3 indicate the load levels at which the corresponding crack tip was observed. By this way, the crack distribution and development during the test can be noted

As the load increased, a diagonal shear crack occurred from the outer tip of artificial crack, and then a horizontal crack appeared and propagated along the level of the tension steel reinforcement, contributing to the separation of the concrete cover. For specimens with steel bolt length less than $120 \mathrm{~mm}$, the full separation of cantilever was observed. For specimens with steel bolt length equal to $120 \mathrm{~mm}$, no failure of cantilever occurred. Finally, flexure failure was observed for all of the specimens, with concrete crushing after the yielding of tension reinforcement. For specimens of group Lc, one diagonal shear crack initiated from the location of anchorage at the last period of the loading process, which was not observed in other groups. No delamination was observed between concrete and CFRP laminates during the whole loading process for all specimens.

\subsection{Load-strain response}

In order to clarify the failure mechanism of beam-type cantilevers with different numbers and sizes of steel bolt anchorages, the typical load-strain relationships of some specimens are plotted in Fig. 4. Some illogical results were observed from the strain gauges' response such as the difference between strain gauges FRP-1 and FRP-2 of the same specimen, the negative value (compressive strain) of some of the strain reads (mainly for strain of stirrups), etc. The difference of the strain response of strain gauges of FRP-1 and FRP-2 may be explained as follows: two separate CFRP strips instead of one CFRP strip were bonded to the soffit of cantilever to leave the space for anchorage installation, as indicated in Fig. 1, and stain gauges FRP-1 and FRP-2 were attached on the respective CFRP strip. The two CFRP strips may not behave as monolithically as one strip and therefore the outputs of strain gauges FRP-1 and FRP-2 differed from each other although they are in the same session. Another important reason is to the reliability of the strain gauge measurement during the unbalance 
event, yielding, cracking, etc., as also observed and explained by other researchers [43-45]. However, the illogical values are only for very limited number of strain gauges and the following discussions can still be raised regarding the general tendency of the strain response.

The strain of tension reinforcement and CFRP increased almost linearly with the load at the initial stage. When a horizontal crack finally passed through the whole cantilever section, a sudden drop (knee point marked by circle in Fig. 4) was found for the strain of CFRP, corresponding to a sudden rise of the strain of tension reinforcement. For specimens with anchorage lengths less than $120 \mathrm{~mm}$ or without anchorage (Fig. 4.a, 4.c and 4.d), the strain of CFRP laminate could not be recovered after the sudden drop, indicating the loss of CFRP strengthening efficiency. For specimens with anchorage length of $120 \mathrm{~mm}$, the strain of CFRP laminate was restored and even further increased, showing that concrete cover separation was well suppressed. All the strain outputs of the stirrups showed relative small values, even to the end of loading. Fig. 5 shows the CFRP laminate's strain curve of all specimens. Except for beams with a $120 \mathrm{~mm}$ long steel bolt, almost all specimens' curves have a sudden strain drop point, which corresponded to the full separation of cantilevers.

\subsection{Debonding load at failure of cantilevers}

According to the above stated criteria, the corresponding full cantilever separation load deduced from the load-strain curves and the failure modes are listed in Table 2. $P_{\text {exp }}$ represents the debonding load obtained from test.

Fig. 6 shows the comparison of the average cantilever failure load (debonding load) of each series. For each series, the debonding load was improved with an increase of steel bolt length. For specimens with $120 \mathrm{~mm}$ steel bolts, no full separation of cantilever was observed and therefore not listed in the figure. For the La-50 series, the debonding load was lower than that of Ld-0, which may be attributed to the fact that short steel bolts could be pulled out soon after the separation of the cantilever, leaving the pre-set holes weakening the tensile resistance of the cantilever. This brings a concept of shortest anchorage, below which an adverse effect of anchorage is possible. On the other hand, $\mathrm{Lb}$ and $\mathrm{Lc}$ series with anchorage lengths of $50 \mathrm{~mm}$ showed higher debonding loads than that of Ld-0, which showed the effect of anchorage location and anchorage number as described below.

The effect of $d_{a}$ depends on the location of the steel bolt and the relationship between the steel bolts' pulling out force and the load of full cantilever separation. Taking La-50 and Lb-50 for comparison, if the steel bolt was pulled out before full cantilever separation, larger the $d_{a}$, the greater the tensile force generated in the steel bolt, leading to a faster pull-out failure of the steel bolt and a lower debonding load. On the other hand, for La-70 and 
Lb-80, when the pull-out force of the steel bolt is greater than the full cantilever separation load, the steel bolt can suppress the propagation of horizontal cracks and therefore a larger $d_{a}$ resulted in a higher failure load. For group Lc-70, the debonding load was less than that of group La-70. This may be due to the appearance of vertical cracks from the location of the inner anchors as shown in Fig. 3.c, which actually separated one cantilever into two adjacent cantilevers of small lengths. Generally, the multi-anchors in the same concrete tooth showed no clear increased effect on full cantilever separation load. The above discussion can be further clarified with the following analytical models.

\section{Analytical model}

The experimental observations suggest that the failure of the CFRP strengthened cantilevers with steel bolt anchorage is controlled by two factors. The first factor is the initiation of cantilever separation and full separation of cantilever, which is related to the materials, geometry, and location of the cantilever. Another factor is the condition required to reach the pull-out failure of the steel bolts, which is related to the performance, length, anchored number, and location of the steel bolts. Additionally, since the shear crack initiated before the cantilever separation, the effect of the diagonal shear crack should be considered in the analytical model.

\subsection{The pull-out modes of steel bolts}

The pull-out modes of steel bolts based on the pull-out test could be divided into five cases [46] as shown in Fig. 7: (a) concrete-cone failure; (b) failure of the interface between concrete and epoxy resin; (c) combination failure of the concrete-cone and concrete-resin interface; (d) failure of the interface between steel bolt and epoxy resin; (e) combination failure of concrete-cone and bolt-resin interface. Due to the page limitation, more details regarding the five failure modes and the differences among them can be found in references [46-47] and will not be repeated in this paper. In this experiment, a nut was used at the end of the steel bolts to avoid failure modes (d) and (e), which were actually not observed during the testing. Therefore, only modes (a), (b) and (c) are discussed hereafter. Moreover, an assumption of uniform distribution of shear stress on concrete-resin interface was adopted because the anchorage length was small.

For model (a), the pull-out force of one single steel bolt is [47]:

$$
P=\pi\left(L^{2}+D_{0} L\right) f_{\mathrm{t}}
$$

where $D_{0}$ and $L$ are the diameter and effective height of the preset hole in $\mathrm{mm}$, respectively; $f_{\mathrm{t}}$ is the tensile strength of the concrete in MPa.

For model (b), the pull-out force of one single steel bolt is 


$$
P=\pi D_{0} L \tau_{\text {poc }}
$$

where $\tau_{p o c}$ is the average shear strength of the concrete-resin interface, which was 6.94 Mpa obtained from a pullout test of a steel bolt.

For model (c), assuming the height of the concrete-cone is $x$, the pull-out force of one single steel bolt will be:

$$
\begin{aligned}
& P=\pi\left(x_{1}^{2}+D_{0} x_{1}\right) f_{\mathrm{t}}+\pi D_{0}\left(L-x_{1}\right) \tau_{\mathrm{poc}} \\
& x_{1}=\frac{1}{2}\left(\frac{\tau_{\mathrm{poc}}}{f_{\mathrm{t}}}-1\right) D_{0}
\end{aligned}
$$

Eq. 4 can be obtained by taking the derivative of Eq. 3, and the value is equal to $16.72 \mathrm{~mm}$ for the anchorage system used in this study. However, considering the effect of the diagonal crack, the failure mode needs to be modified. The failure surface of the steel bolt anchorage under the shearing crack is shown in Fig. 8. The angle between the shear diagonal crack and the cantilever end section is assumed to be $45^{\circ}$.

Fig.8 indicated the effect of diagonal cracking on the failure mode of embedded anchors. The effect of diagonal cracks was regarded as: 1. dividing the embedded anchorage to be two parts, namely upper part and lower part to lead to stress redistribution along the anchorage and its surrounding concrete; 2. causing the loss of the concrete cone resistance at the diagonal crack side, such that the anchorage pull-out strength is reduced.

Based on the basic modes (Fig. 7), there are three different cases considering the effect of diagonal crack as shown in Fig. 8:

Case(a) If $2 L<S_{c r^{-}} d_{a}$, the shear crack is far away from the embedment failure surface of steel bolt. Therefore, the effect of the shear crack could be ignored and would not change the failure surface of the steel bolt anchorage. The pull-out mode will be mode (a) when $L<x$ (Fig. 8 (a. 1)) or mode (c) when $S_{c r}-d_{a}>x$ (Fig. 8 (a. 2)).

Case(b) If $\left(S_{c r}-d_{a}\right) / 2<L<S_{c r}-d_{a}$, because of the effect of the shear crack, only half of the original failure surface was assumed to act, and the other half was the crack surface which had no resistance. Therefore, the pullout mode of anchor will be mode (a) when $L<x$ (Fig.8 (b. 1)) or mode (c) when $S_{c r}-d_{a}>x$ (Fig.8 (b. 2)) and the force is taken to $0.5 \mathrm{P}$ as a reduction;

Case(c) If $S_{c r}-d_{a}<L$, the embedded anchorage was divided to two parts. For the lower part, it follows the same rule as case (b), and thus the concrete below the shear crack will fail by mode $(\mathrm{a} / \mathrm{c})$. For the upper part, it will forms a half-cone: the side (close to the tensile end of cantilever) of the steel bolt fails by mode (b), and the 
other side will be failed still by mode (a) $L<S_{c r}-d_{a}+x$ (Fig.8 (c. 1) ) or mode (c) when $L>S_{c r}-d_{a}+x$ (Fig.8 (c. 2)). Similarly, only a half of the upper half cone surface was considered to be effective.

\subsection{Full cantilever separation mode with steel bolts}

The anchor's effect on the onset of the shear crack is ignored, meaning the anchor takes effect only after the start of the shear crack. The effective bond length of anchor $L$ for resisting the pull-out force generated by the tension force of external reinforcement is $l_{a}-h_{0}$.

As shown in Fig. 9, a signal concrete tooth actually performs as a deep cantilever, which means adopting the plain assumption is not appropriate anymore. However, considering the convenience and popular use of the plain assumption in practical design, assumption of linear strain distribution is still used in the present model, while modified with an influence coefficient of deep beam effect $\gamma$ based on the "Design code requirements for deep beam of reinforced concrete" (CECS39-92)[48]:

$$
\gamma=1.15+0.08 h_{0} / S_{c r}\left(\text { if } h_{0} / S_{c r} \leq 1, h_{0} / S_{c r}=1\right)
$$

Considering the effect of the anchor before and after the full cantilever separation, the sectional analysis is as follows:

The concrete tensile stress generated at point $\mathrm{A}\left(\sigma_{A c}\right)$ before full cantilever separation is:

$$
\sigma_{A c}=\frac{M_{A}}{I_{a 1} \gamma}\left(S_{c r}-x_{a 1}\right)
$$

The anchor tensile stress generated at the interface is:

$$
\begin{aligned}
& \sigma_{a}=\frac{E_{a} M_{A}}{E_{c} I_{a 2} \gamma}\left(d_{a}-x_{a 2}\right) \quad \text { after initiation of cantilever separation } \\
& M_{A}=\sigma_{f B} t_{f} b_{f} h_{0}
\end{aligned}
$$

where $\sigma_{f B}, t_{f}$, and $b_{f}$ are the tensile stress of thickness and width of the CFRP at point B, respectively. $I_{a 0}$ and $x_{a 0}$ are the moment of inertia of a cantilever without anchorage in terms of concrete and the neutral axis depth before cantilever separation, respectively. $I_{a 2}$ and $x_{a 2}$ are the moment of inertia of an anchored cantilever in terms of concrete and the neutral axis depth after cantilever separation, respectively.

The concrete tensile stress generated at point $\mathrm{A}\left(\sigma_{A c}\right)$ when cantilever fully separated is:

$$
\sigma_{A c}=\frac{\sigma_{f} t_{f} b_{f} h_{0}}{I_{a 1} \gamma}\left(S_{c r}-x_{a 1}\right)=f_{t l}
$$


where $f_{t l}$ is the tensile strength of concrete considering the effect of shear stress at the fracture surface; $\gamma$ is the coefficient of deep beam effect; $I_{a l}$ and $x_{a l}$ are the moment of inertia of an anchored cantilever in terms of concrete and the neutral axis depth before cantilever separation, respectively. The cantilever is actually subjected to a combined shear and tensile (compressive) stress. For a cantilever without anchorage, According to the Mohr-Coulomb criterion:

$$
f_{t l}=\left(f_{t}-\frac{\sigma_{f} t_{f} b_{f} f_{t}}{b S_{c r} \tau}\right)
$$

where $\tau$ is the shear strength of concrete, and could be derived from $f_{c u}$.

According to Eqs.5-8, the tension stress of CFRP at point B could be derived as:

$$
\sigma_{f B 1}=\frac{f_{t} I_{a 1} b S_{c r} \tau \gamma}{t_{f} b_{f} h_{0}\left(S_{c r}-x_{a 1}\right) b S_{c r} \tau+I_{a 1} t_{f} b_{f} f_{t} \gamma}
$$

According to Eq.6, for specimens with steel bolt anchorage, the CFRP tensile stress generated at point B when the anchor is pulled out $\left(\sigma_{a}=P_{a} / A_{a}\right)$ is

$$
\sigma_{f B 2}=\frac{E_{c} P_{\mathrm{a}} I_{a 2} \gamma}{E_{a} A_{a} t_{f} b_{f} h_{0}\left(d_{a}-x_{a 2}\right)} \text { after initiation of cantilever separation }
$$

If $\sigma_{f B 1} \geq \sigma_{f B 2}$, the anchorage will be pulled out right after the initiation of cantilever separation, and the cantilever top section stiffness is actually decreased. In this case, $I_{a l}$ and $x_{a l}$ in Eq. 10 should be modified to $I_{a l}$, and $x_{a l}$ ' based on the weakened section and the corresponding $\sigma_{f B 1}$ is changed to:

$$
\sigma_{f B 1}{ }^{\prime}=\frac{f_{t} I_{a 1}{ }^{\prime} b S_{c r} \tau \gamma}{t_{f} b_{f} h_{0}\left(S_{c r}-x_{a 1}{ }^{\prime}\right) b S_{c r} \tau+I_{a 1}{ }^{\prime} t_{f} b_{f} f_{t} \gamma}
$$

Fig. 10 presents the proposed calculation procedure. There are three cases for the cantilever depending on the value of $\sigma_{f B 1}, \sigma_{f B 1}$ ', $\sigma_{f B 2}$, corresponding to respective possible failure of the anchored cantilever.

After obtaining $\sigma_{f B 1}, \sigma_{f B 1}$,,$\sigma_{f B 2}$, the following criterions are adopted to determine the failure modes and maximum strain of CFRP laminate at point B $\left(\sigma_{f B, \max }\right)$ :

(1) For specimens without anchorage $\left(l_{a}-h_{0}>0\right), \sigma_{f B, \max }=\sigma_{f B 1}$;

(2) For specimens with anchorage $\left(l_{a}-h_{0}>0\right)$, the anchorage is pulled out after the initiation of cantilever separation and the following two possible failure modes are:

(a) If $\sigma_{f B 1} \geq \sigma_{f B 2}$, the anchorage is pulled out right after the initiation of cantilever separation, $\sigma_{f B, \max }=\sigma_{f B 1}$ '.

(b) If $\sigma_{f B 2}>\sigma_{f B 1}$, the anchorage can still contribute after the initiation of cantilever separation, and the full cantilever separation is determined by the pull-out strength of the steel bolt, $\sigma_{f B, \max }=\sigma_{f B 2}$. 

separation can then be determined as:

$$
P_{d i}=\frac{2 M_{d i}}{\left(d_{0}+S_{c r}\right)}
$$

where $M_{d i}$ is the moment on the beam section derived from $\sigma_{f B, \max }$ according to Teng et al.'s (2002) proposal [1] on calculating the flexural strength of FRP strengthened RC beams. For a single tooth with more than one anchor (Group Lc), a similar procedure was adopted with consideration of the location and depth of each anchor.

The predicted full cantilever separation loads (debonding loads) are listed in Table 2. To examine the applicability of the proposed models to predict cantilever separation, the calculated full cantilever separation load is compared with the experimental results as shown in Fig. 11. For CFRP strengthened RC structures with end steel bolt anchorage, the mean value of the ratio between the calculated and experimental full cantilever separation loads $\left(P_{\text {exp }} / P_{\text {cal }}\right)$ is 1.03 , with a deviation of 0.027 . The proposed model closely predicts the effects of various parameters such as the dimensions of the steel bolts and the material properties.

\subsection{Parametric studies of anchored cantilever}

Based on the proposed analytical model, the full separation load of the cantilever with different concrete strength and geometry could be calculated. The beam-type cantilever used for parametric analysis follows the same setup as the specimen in the previous experimental sessions. Fig. 12 presents the analytical results for specimens without anchorage (Fig. 12.a and 12.b) and with anchorage (Fig. 12.c) to illustrate the effect of cantilever strength and geometry (height and width) and the effect of steel bolt on its full separation load. As shown in the Fig. 12.a and 12.b, the full separation load increases with the concrete compressive strength, which is attributed to the fact that the full separation of cantilever was actually governed by the tensile and shear strength of concrete. Moreover, the full separation load of cantilever increases with width of cantilever while decreases with height of cantilever, which indicates the positive effect of moment of inertia (proportional to cantilever width) and negative effect of the arm of force (proportional to cantilever height) of the cantilever. Fig 14.c shows the predicted full separation loads for specimens with different length and location of the steel anchorage. With larger $l_{a}$ and $d_{a}$, the full separation load of the cantilever generally becomes bigger. However, when the steel bolt is too short $\left(l_{a} \leqslant 60 \mathrm{~mm}\right)$ and pulled out soon after the initiation of separation of cantilever, a larger $d_{a}$ will result in a smaller full separation load. The weakened concrete section due to pull out of steel bolt has more negative effect to the full separation load when it has larger distance to the compressive end $\left(d_{a}\right)$. This 
also agrees well with the experimental results. Therefore, the anchorage should be long enough to resist pull out force after the initiation of cantilever separation, such that the full separation strength of cantilever can be enhanced by the anchorage system.

Note that the current study focused only on the short-term performance of the anchored cantilever, further study needs to be carried out to clarify its long-term performance under combined load and environmental impacts to improve the applicability of the proposed models in the real engineering applications.

\section{Conclusions}

The behaviors of CFRP laminates strengthened beam-type cantilevers with and without steel bolt anchorages were experimentally investigated. The effects of steel bolt length and the horizontal distance from the center of the steel bolts to the left artificial crack were analyzed. Several conclusions can be made based on the test results:

1. The proposed beam-type cantilever test can be used to investigate the mechanism of concrete cover separation. The load at the full cantilever separation can be determined by the knee point in the load-strain response curves of CFRP laminate at the end of the cracked section of the cantilevers.

2. If steel bolts are pulled out before full cantilever separation, the debonding load of the concrete cover remains unchanged or even decreases because of the stiffness reduction of the concrete cover failure section after the steel bolts were pulled out. The greater the distance from the steel bolt to the cantilever compression end $\left(d_{a}\right)$, the greater is the tension force generated in the bolt. Better performance of the anchorage can be realized if the length of the steel bolt is long enough, as it prevents or postpones the concrete cover separation.

3. In case of a multi-anchorage, the steel bolt with largest distance to the compression side of the cantilever takes the dominant function of the anchorages. The multi-anchors in the same concrete tooth didn't show a clear increase in full cantilever separation load.

4. Based on the concrete tooth model and beam-type cantilever test, a simple analytical approach is proposed, considering various possible failure modes of anchors and cantilevers. The reliability and accuracy of the proposed analytical procedure were verified against the test results.

\section{Acknowledgments}


(GDDCE15-11) are greatly appreciated.

\section{References}

[1] Teng JG, Smith ST, Yao J, Chen JF. Intermediate crack-induced debonding in RC beams and slabs.

[2] Hollaway L, Teng J-G. Strengthening and Rehabilitation of Civil Infrastructures Using FibreReinforced Polymer (FRP) Composites. 2008. doi:10.1533/9781845694890.1.

[3] Ueda T, Dai J. Interface bond between FRP sheets and concrete substrates: Properties, numerical modeling and roles in member behaviour. Prog Struct Eng Mater 2005;7:27-43. doi:10.1002/pse.187.

[4] Buyukozturk O, Gunes O, Karaca E. Progress on understanding debonding problems in reinforced concrete and steel members strengthened using FRP composites. Constr Build Mater 2004;18:9-19. doi:10.1016/S0950-0618(03)00094-1.

[5] Dai J, Ueda T, Sato Y. Bonding characteristics of fiber-reinforced polymer sheet-concrete interfaces under dowel load. J Compos Constr 2007;11:138-48. doi:10.1061/(ASCE)1090-0268(2007)11:2(138).

[6] Gao WY, Teng JG, Dai J-G. Effect of Temperature Variation on the Full-Range Behavior of FRP-toConcrete Bonded Joints. J Compos Constr 2012;16:671-83. doi:10.1061/(asce)cc.1943-5614.0000296

[7] Tuakta C, Büyüköztürk O. Deterioration of FRP/concrete bond system under variable moisture conditions quantified by fracture mechanics. Compos Part B Eng 2011;42:145-54. doi:10.1016/j.compositesb.2010.11.002.

[8] Zhou, A., Büyüköztürk, O., \& Lau, D. Debonding of concrete-epoxy interface under the coupled effect of moisture and sustained load. Cem Concr Compos 2017;80:287-97. doi:10.1016/j.cemconcomp.2017.03.019.

[9] Zhou A, Qin R, Feo L, Penna R, Lau D. Investigation on interfacial defect criticality of FRP-bonded concrete beams. Compos Part B Eng 2017;113:80-90. doi:10.1016/j.compositesb.2016.12.055.

[10] Yao J, Teng JG. Plate end debonding in FRP-plated RC beams-I: Experiments. Eng Struct 2007;29:2457-71. doi:10.1016/j.engstruct.2006.11.022.

[11] Zhang D, Ueda T, Furuuchi H. Concrete cover separation failure of overlay-strengthened reinforced concrete beams. Constr Build Mater 2012;26:735-45. doi:10.1016/j.conbuildmat.2011.06.082.

[12] Zhang D, Ueda T, Furuuchi H. A design proposal for concrete cover separation in beams strengthened by various externally bonded tension reinforcements. J Adv Concr Technol 2012;10:285-300. doi:10.3151/jact.10.285.

[13] Dai J-G, Wan B-L, Yokota H, Ueda T. Fracture Criterion for Carbon Fiber Reinforced Polymer Sheet to Concrete Interface Subjected to Coupled Pull-out and Push-off Actions. Adv Struct Eng 2009;12:663-82. doi:10.1260/136943309789867917.

[14] Zhang D, Ueda T, Furuuchi H. Intermediate Crack Debonding of Polymer Cement Mortar OverlayStrengthened RC Beam. J Mater Civ Eng 2011;23:857-65. doi:10.1061/(ASCE)MT.1943-5533.0000240.

[15] Raoof M, Wood L a, Zhang S. Prediction of peeling failure of reinforced concrete beams with externally bonded steel plates. Proc ICE-Structures Build 1995;110:257-68. doi:10.1680/istbu.1995.27870.

[16] Hassanen M a. H, Raoof M. Peeling failure of reinforced concrete beams with fibre-reinforced plastic or steel plates glued to their soffits. Proc ICE - Struct Build 2000;140:291-305. doi:10.1680/stbu.2000.140.3.291.

[17] Kalfat R, Al-Mahaidi R, Smith S. Anchorage Devices Used to Improve the Performance of Reinforced Concrete Beams Retrofitted with FRP Composites: State-of-the-Art Review. J Compos Constr 2011;17:14-33. doi:10.1061/(ASCE)CC.1943-5614.0000276.

[18] Sallam HE-DM, Saba A-AM, Shahin HH, Abdel-Raouf H. Prevention of peeling failure in plated beams. J Adv Concr Technol 2004;2:419-29.

[19] Garden HN, Hollaway LC. An experimental study of the influence of plate end anchorage of carbon fibre composite plates used to strengthen reinforced concrete beams. Compos Struct 1998;42:175-88. doi:10.1016/S0263-8223(98)00070-1.

[20] Spadea G, Bencardino F, Swamy RN. Structural behavior of composite RC beams with externally bonded CFRP. J Compos Constr 1998:132-7.

[21] Duthinh D, Starnes M. Strengthening of Reinforced Concrete Beams with Carbon FRP. Compos Constr 
Figueiras Al 2001;1.

[22] Bank LC, Arora D. Analysis of RC beams strengthened with mechanically fastened FRP (MF-FRP) strips. Compos Struct 2007;79:180-91. doi:10.1016/j.compstruct.2005.12.001.

[23] Smith ST, Teng JG. Shear-Bending Interaction in Debonding Failures of FRP-Plated RC Beams. Adv Struct Eng 2003;6:183-99. doi:10.1260/136943303322419214.

[24] Al-Amery R, Al-Mahaidi R. Coupled flexural-shear retrofitting of RC beams using CFRP straps. Compos Struct 2006;75:457-64. doi:10.1016/j.compstruct.2006.04.037.

[25] Pham HB, Al-Mahaidi R. Prediction Models for Debonding Failure Loads of Carbon Fiber Reinforced Polymer Retrofitted Reinforced Concrete Beams. J Compos Constr 2006;10:48-59. doi:10.1061/(ASCE)10900268(2006)10:1(48).

[26] Yalim B, Kalayci AS, Mirmiran A. Performance of FRP-Strengthened RC Beams with Different Concrete Surface Profiles. J Compos Constr 2008;12:626-34. doi:10.1061/(ASCE)1090-0268(2008)12:6(626).

[27] Lam L, Teng JG. Strength of RC cantilever slabs bonded with GFRP strips. J Compos Constr 2001;5:221-7. doi:10.1061/(ASCE)1090-0268(2001)5:4(221).

[28] Eshwar N, Ibell TJ, Nanni A. Effectiveness of CFRP strengthening on curved soffit RC beams. Adv Struct Eng 2005;8:55-68. doi:10.1260/1369433053749607.

[29] Micelli F, Rizzo A, Galati D, Micelli F, Rizzo A. Anchorage of composite laminates in RC flexural beams. Struct Concr 2010;11:117-26. doi:10.1680/stco.2010.11.3.117.

[30] Zhang HW, Smith ST. FRP-to-concrete joint assemblages anchored with multiple FRP anchors. Compos Struct 2012;94:403-14. doi:10.1016/j.compstruct.2011.07.025.

[31] Sharif A, Al-Sulaimani GJ, Basunbul IA, Baluch MH, Ghaleb BN. Strengthening of initially loaded reinforced concrete beams using FRP plates. ACI Struct J 1994;91:160-8. doi:10.14359/4594.

[32] El Maaddawy T, Soudki K. Strengthening of reinforced concrete slabs with mechanically-anchored unbonded FRP system. Constr Build Mater 2008;22:444-55. doi:10.1016/j.conbuildmat.2007.07.022.

[33] Wu Y, Huang Y. Hybrid Bonding of FRP to Reinforced Concrete Structures. J Compos Constr 2008;12:266-73. doi:10.1061/(ASCE)1090-0268(2008)12:3(266).

[34] Lee JH, Lopez MM, Bakis CE. Slip effects in reinforced concrete beams with mechanically fastened FRP strip. Cem Concr Compos 2009;31:496-504. doi:10.1016/j.cemconcomp.2009.04.008.

[35] Zhang F, Niu P X, Li S C SQY. Experimental analysis on bonding behavior of hybrid-bonding of FRP. J Civ Archit Environ Eng 2010;32.

[36] Wu ZM, Hu CH, Wu YF ZJ. Improved hybrid bonding technique for attaching FRP to reinforced concrete beams. Mag Concr Res 2011;63:861-9.

[37] Sayed-Ahmed EY, Bakay R, Shrive NG. Bond strength of FRP laminates to concrete: State-of-the-art review. Electron J Struct Eng 2009;9:45-61.

[38] Jin Q, Leung CKY. Fiber-Reinforced-Cementitious-Composites Plate for Anchoring FRP Sheet on Concrete Member. J Compos Constr 2011;15:790-8. doi:10.1061/(ASCE)CC.1943-5614.0000211.

[39] Kalfat R, Al-Mahaidi R. Development of a hybrid anchor to improve the bond performance of multiple plies of FRP laminates bonded to concrete. Constr Build Mater 2015;94:280-9. doi:10.1016/j.conbuildmat.2015.07.013.

[40] Guan Y, Jiang B, Song X. Experimental Study and Numerical Simulation on Bonding Behavior of the New HB-FRP Strengthening Technology. J Perform Constr Facil 2011;26:220-7. doi:10.1061/(ASCE)CF.

[41] Lee J, Ph D, Lopez MM, Ph D, Asce M. Characterization of FRP Uwrap Anchors for Externally Bonded FRP-Reinforced Concrete Elements: An Experimental Study. J Compos Constr 2016:1-11. doi:10.1061/(ASCE)CC.1943-5614.0000642.

[42] ACI (American Concrete Institute). (2008). Guide for the design and construction of externally bonded FRP systems for strengthening concrete structures. ACI 440.2R, Farmington Hills, MI.

[43] Sallam HEM. Discussion of " Flexural Strengthening of Steel Bridges with High Modulus CFRP Strips " by David Schnerch and Sami Rizkalla. J BridgEng 2010;15:117-8. doi:10.1061/(ASCE)BE.19435592.72.118

[44] Sallam HEM, Badawy AAM, Saba AM, Mikhail FA. Flexural behavior of strengthened steel-concrete composite beams by various plating methods. J Constr Steel Res 2010;66:1081-7. doi:10.1016/j.jcsr.2010.03.005.

[45] Abd-elhady AA, Sallam HEM. Discussions and Closures Discussion of "Fatigue Behavior of Cracked Steel Plates Strengthened with Different CFRP Systems and Configurations " by Hai-Tao Wang, Gang Wu, and Jian-Biao Jiang 2015:7016002. doi:10.1061/(ASCE)CC.1943-5614.0000647.

[46] Cook RA, Kunz J, Fuchs W, Konz RC. Behavior and design of single adhesive anchors under tensile load in uncracked concrete. ACI Struct J 1998;95:9-26. doi:10.14359/522. 
[47] Zhou X. Anchorage behavior of post-embedded bars in concrete subjected to tension. Chinese J Rock 478 Mech Eng 2003:1169-73.

479 [48] CECS (Chinese Engineering Construction Standard Institute).(1992). Specification for design of reinforced concrete deep beams. CECS39:92. China Building Industry Press, Beijing. 


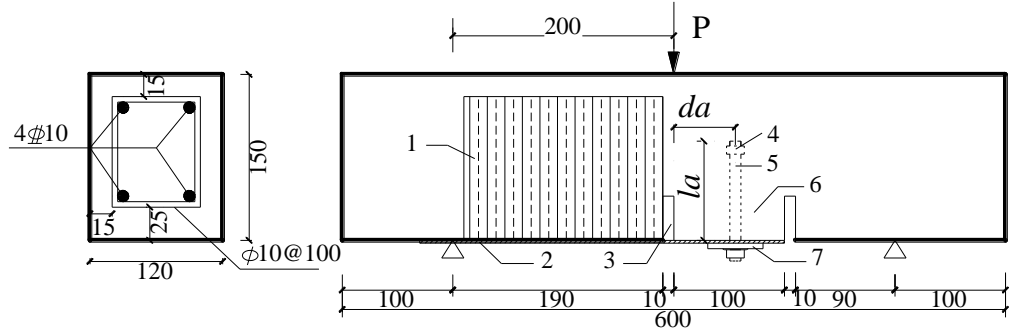

1. CFRP U protecting anchor

2. CFRP laminates

3. artificial crack

4. nut

5. steel bolt anchor

6. beam-type cantiliver

7. steel plate

(a) Side view

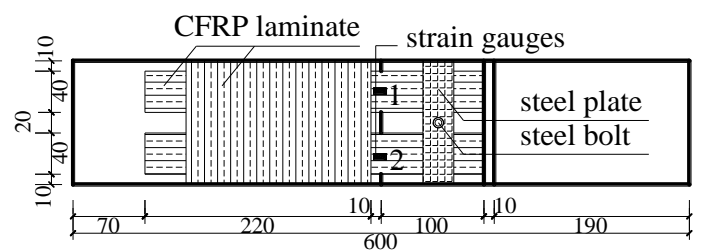

(b) Bottom view of Group La and Lb

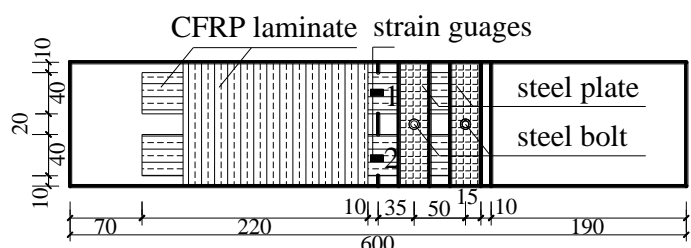

(c) Bottom view of Group Lc

(FRP fiber direction was indicated by dashed lines)

Fig. 1 Geometrical details of the specimens (unit: mm) 


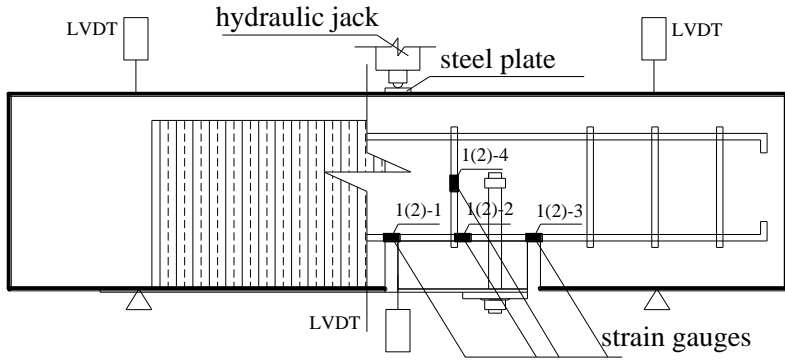

(a) Strain gauge distribution on the reinforcement

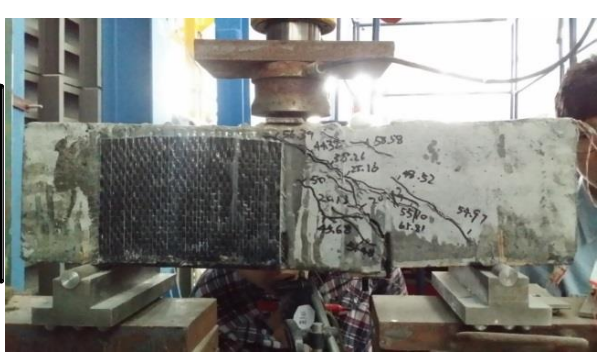

(b) Test setup

Fig. 2 Strain gauge arrangement on the reinforcement and test setup 


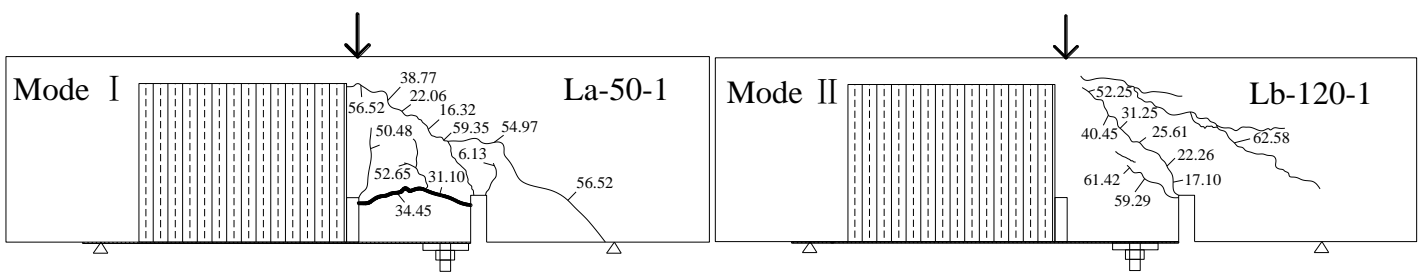

(a) La-50-1

(b) Lb-120-1

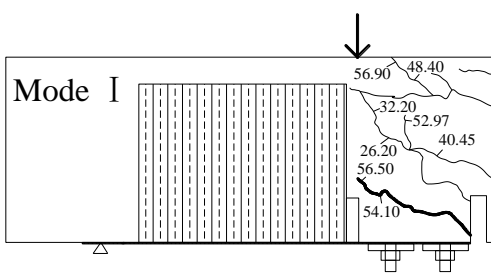

$\downarrow$

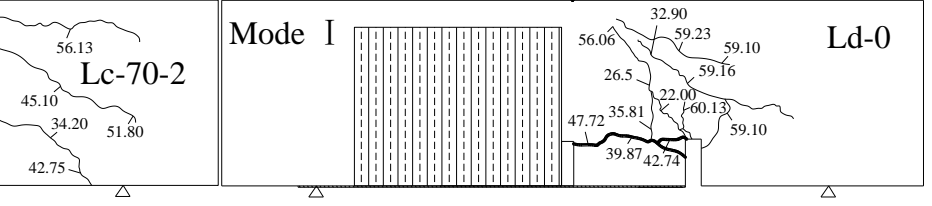

(c) Lc-70-2

(d) Ld-0

Fig. 3 Typical crack distribution (unit: kN) 


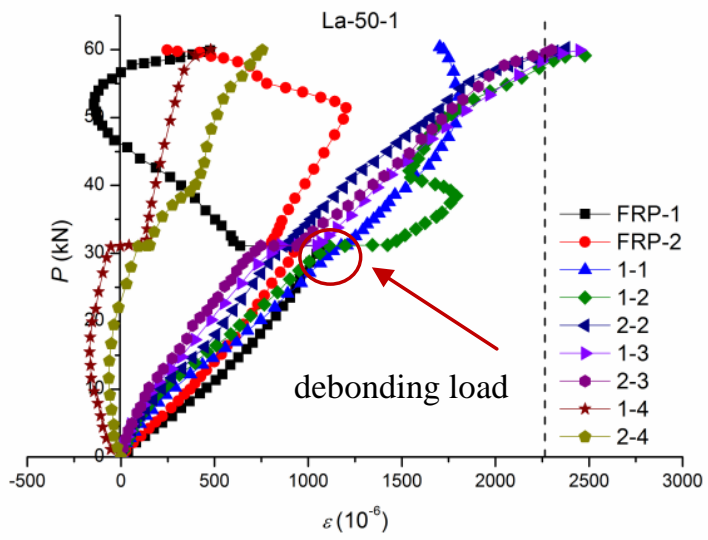

(a) La-50-1

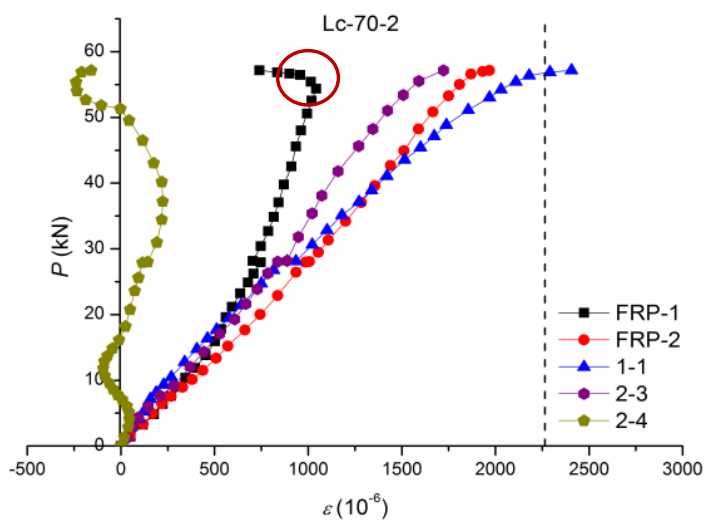

(c) Lc-70-2

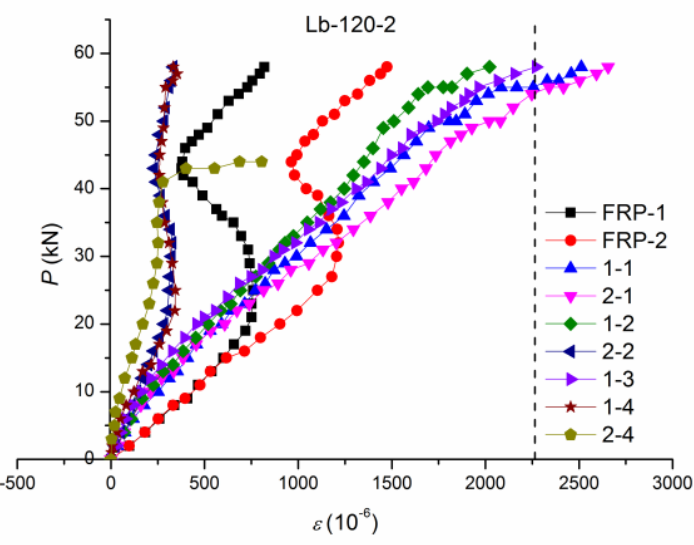

(b) Lb-120-2

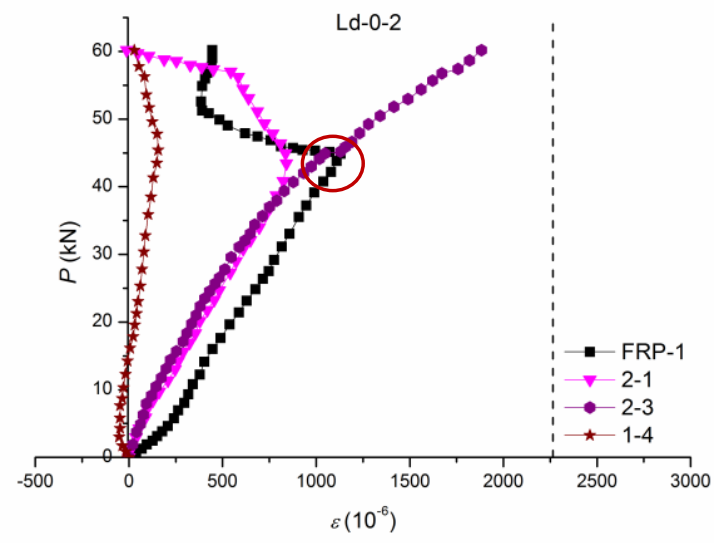

(d) Ld-0

Fig. 4 Load-strain correlation curves 


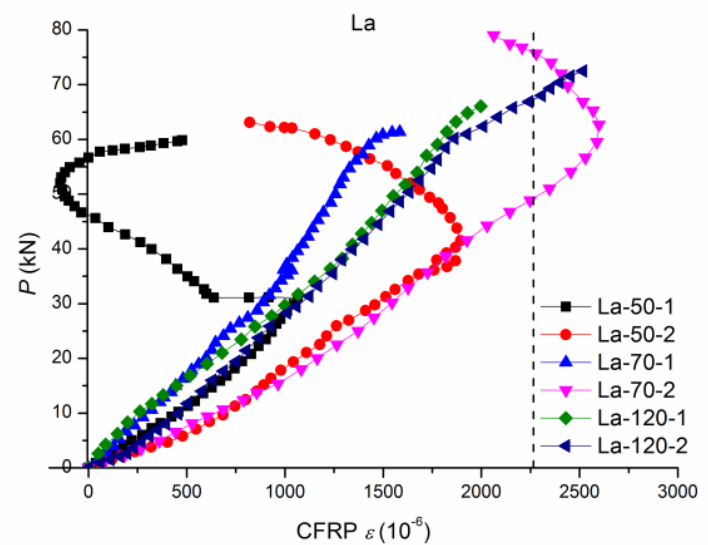

(a) Group La

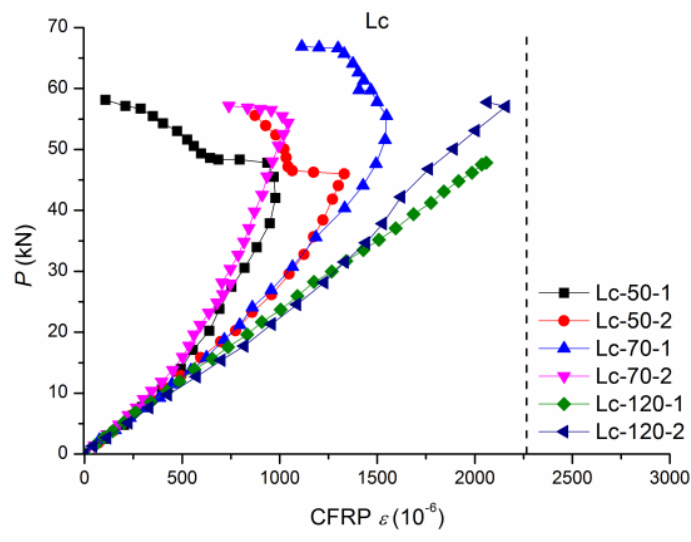

(c) Group Lc

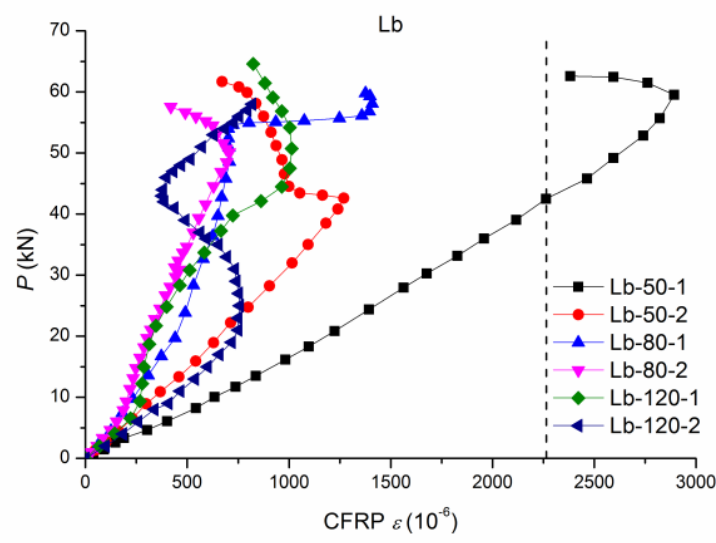

(b) Group Lb

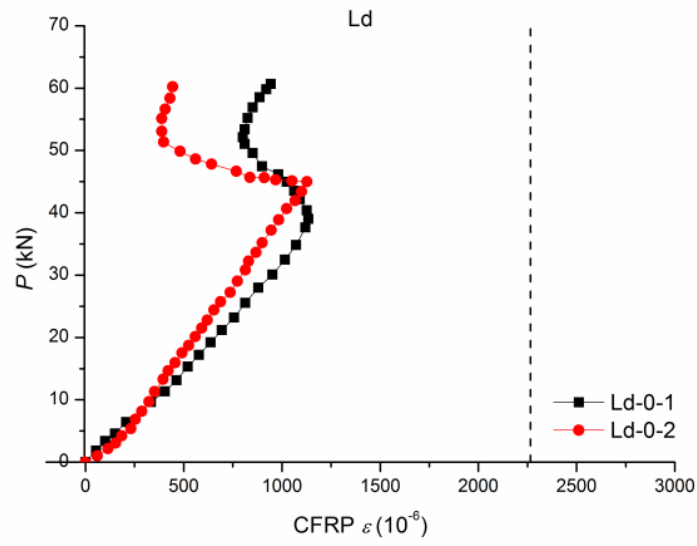

(d) Group Ld

Fig. 5 Load-strain correlation curves of CFRP laminate 


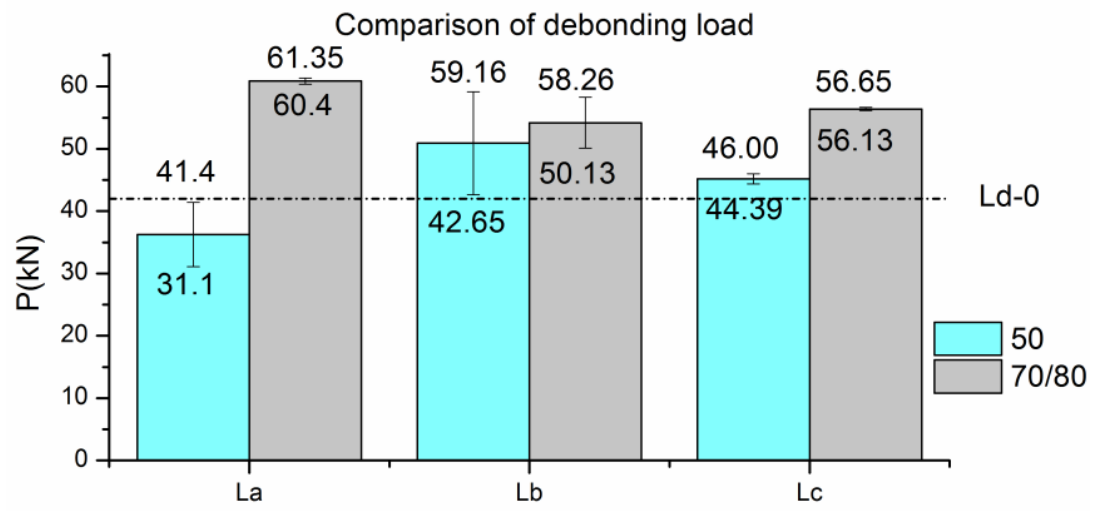

Fig. 6 Comparison of tested full separation load 


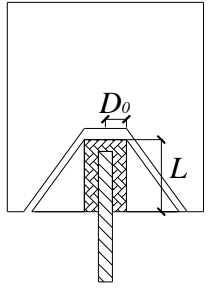

Mode (a)

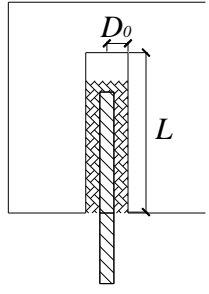

Mode (b)

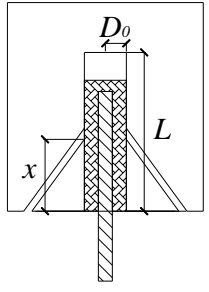

Mode (c)

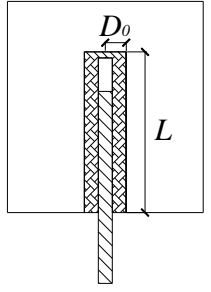

Mode (d)

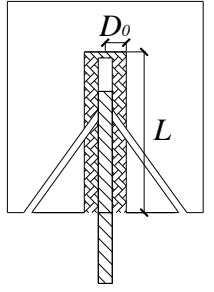

Mode (e)

Fig. 7 Failure modes of steel bolt anchorage 


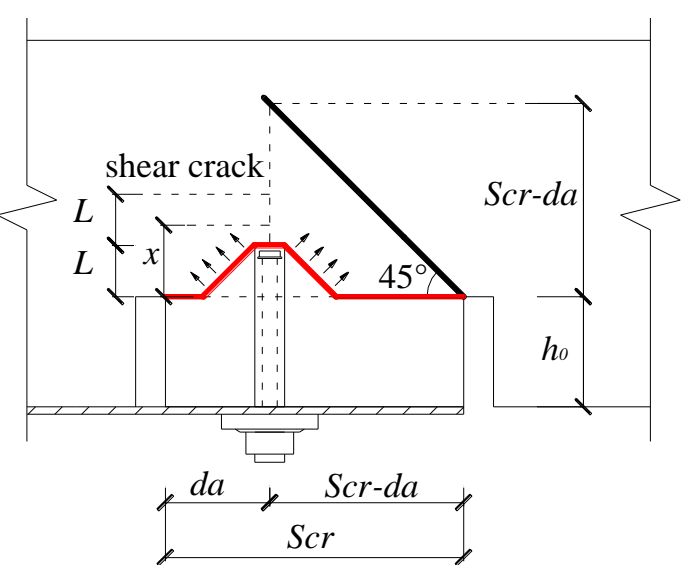

case(a.1)

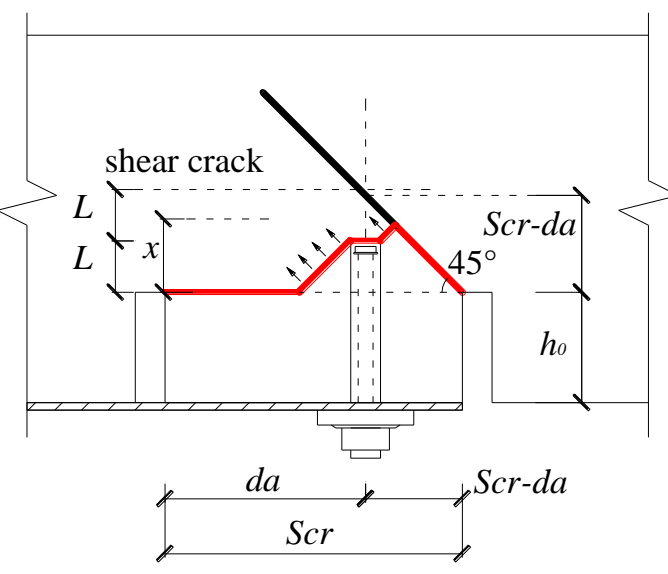

case (b.1)

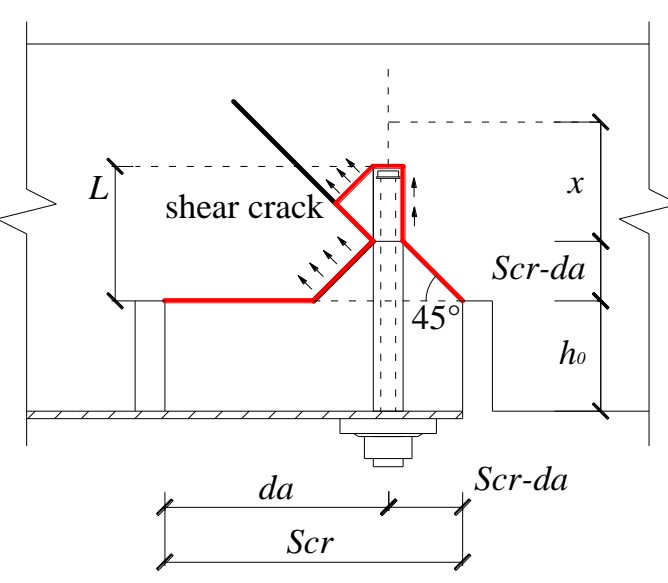

case(c.1)

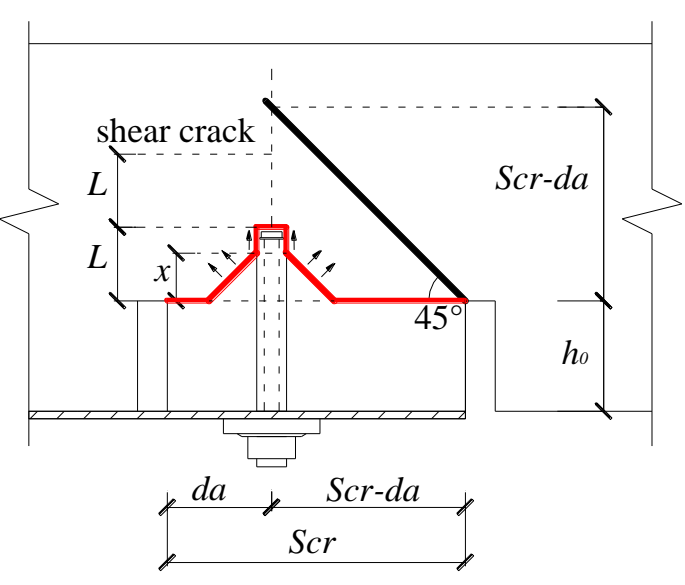

case(a.2)

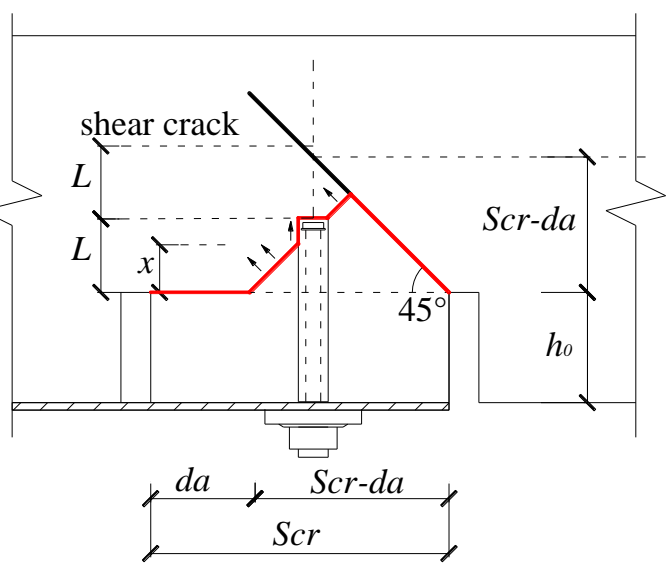

case(b.2)

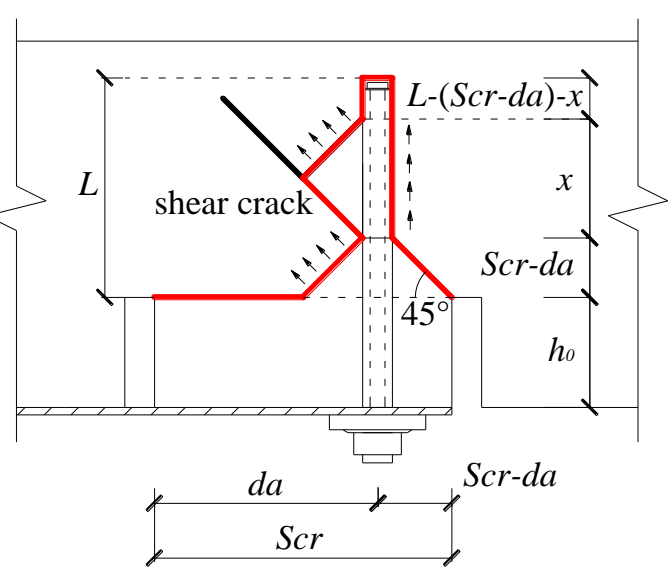

case(c.2)

Fig. 8 Failure surface of the steel bolt anchorage 


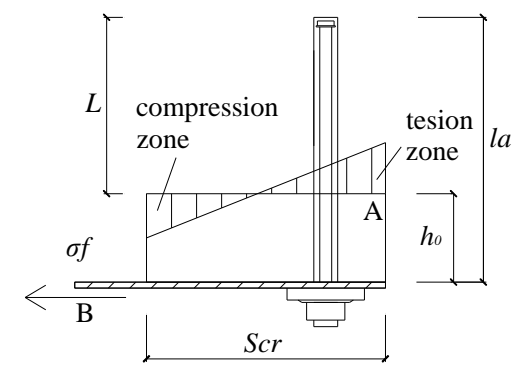

Fig. 9 Strain distribution of the cantilever top end section 


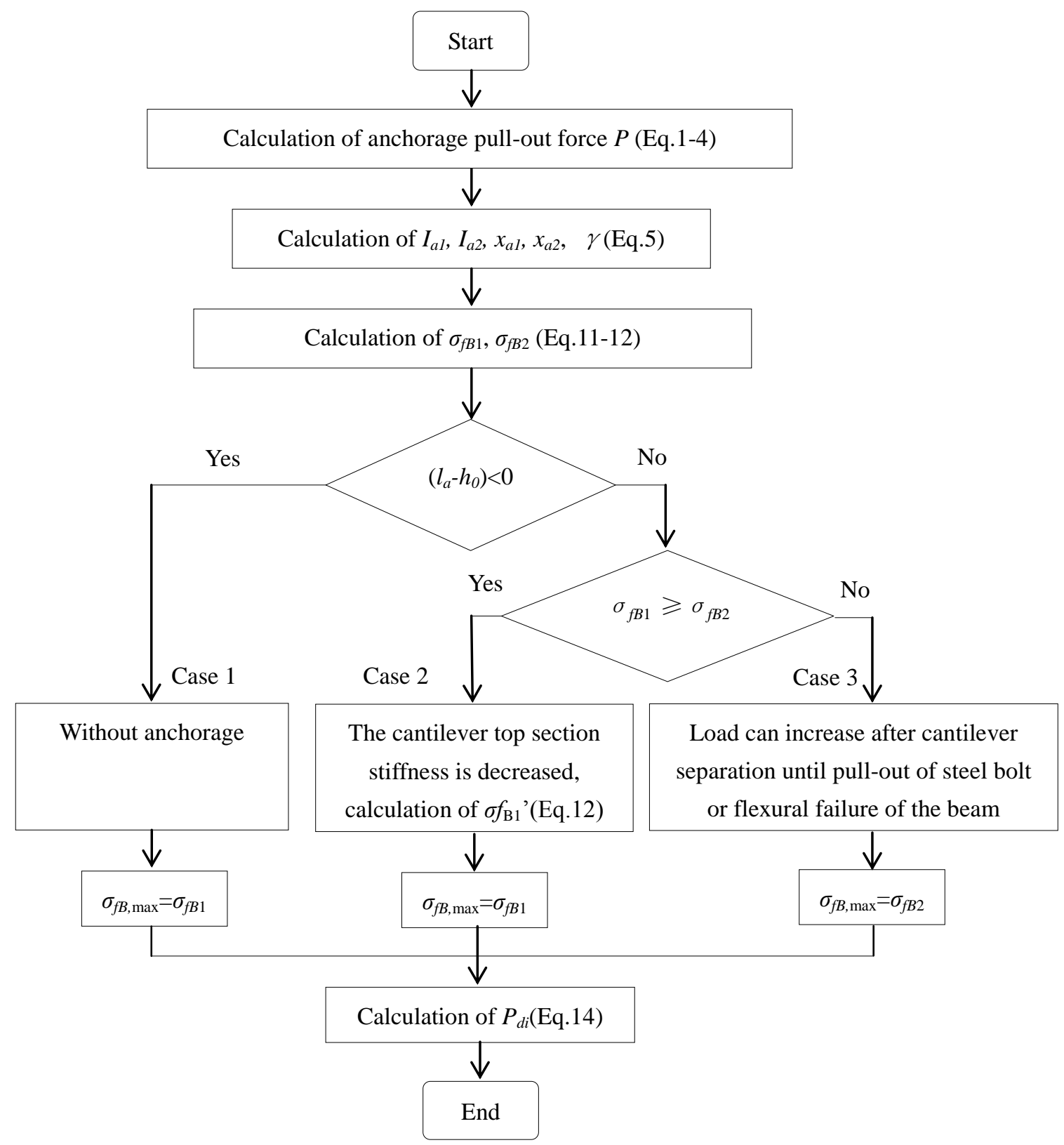

Fig. 10 Calculation flowchart for full cantilever separation 


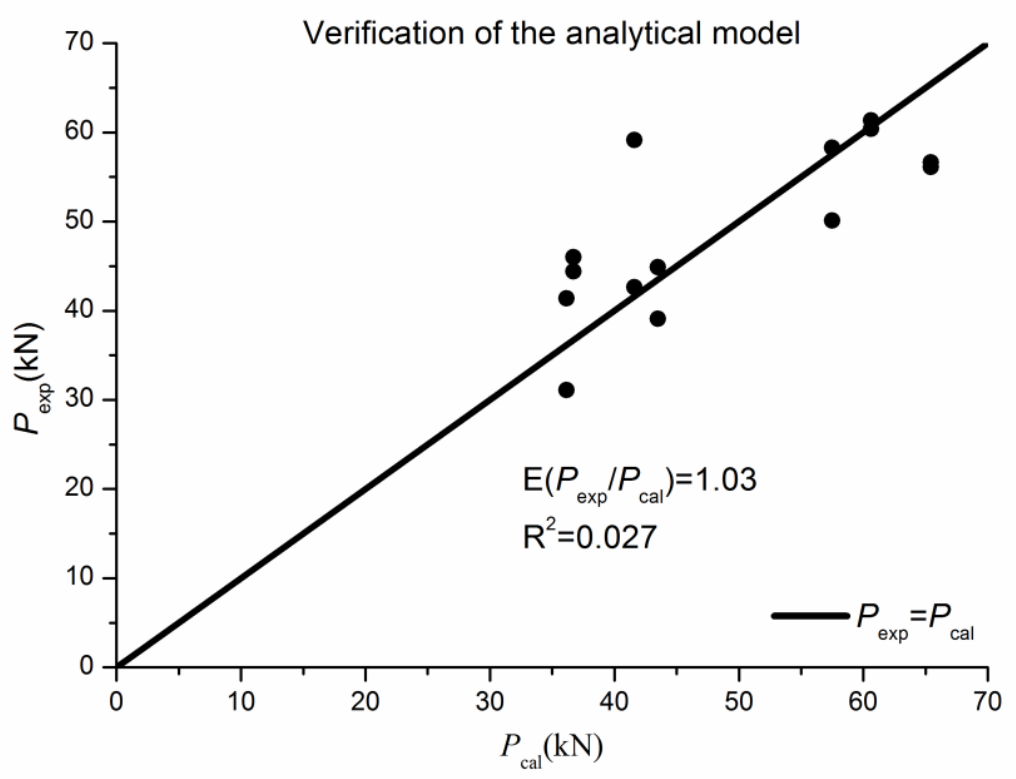

Fig. 11 Comparison between analytical and experimental debonding load 


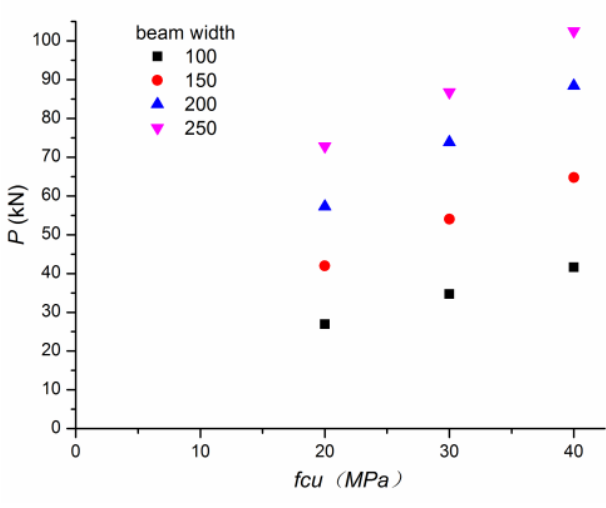

(a) Effect of cantilever width

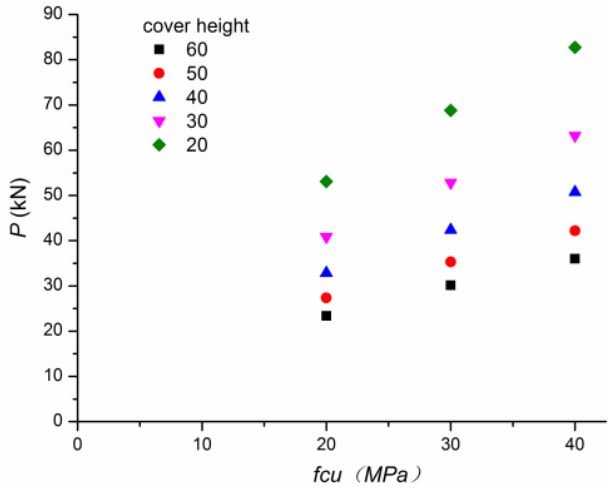

(b) Effect of cantilever height

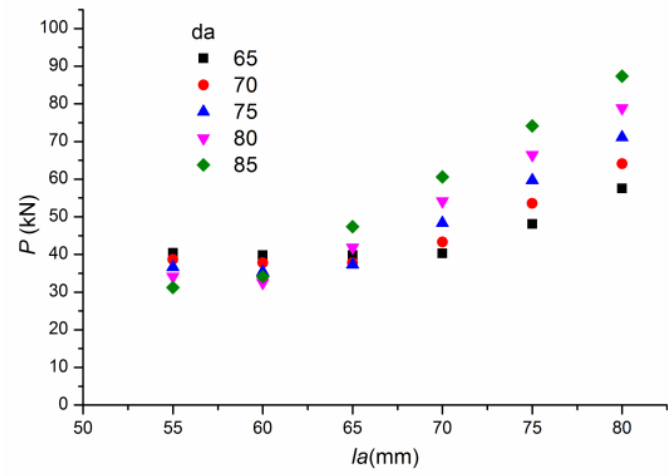

(c) Effect of anchor length and location

Fig. 12 Parametric studies based on the proposed models 
Table 1

Parameters of specimens

\begin{tabular}{lllll}
\hline Group & label & $l_{a} /(\mathrm{mm})$ & $d_{a} /(\mathrm{mm})$ & $n_{t}$ \\
\hline \multirow{4}{*}{ La } & La-50 & 50 & & \\
& La-70 & 70 & 85 & 1 \\
& La-120 & 120 & & \\
\hline \multirow{4}{*}{ Lb } & Lb-50 & 50 & & \\
& Lb-80 & 80 & 65 & 1 \\
& Lb-120 & 120 & & \\
\hline \multirow{4}{*}{ Lc } & Lc-50 & 50 & & \\
& Lc-70 & 70 & $85 / 35^{\text {a }}$ & 2 \\
& Lc-120 & 120 & & \\
\hline Ld & Ld-0 & \multicolumn{4}{l}{ No-anchorage } \\
\hline
\end{tabular}

${ }^{a}$ These two values correspond to the respective distances from the anchor centers to the compression end of cantilever 
Table 2

Experimental values and calculative values

\begin{tabular}{|c|c|c|c|c|}
\hline Group & Label & $P_{\text {exp }}(\mathrm{kN})$ & $P_{c a l}(\mathrm{kN})$ & Failure mode \\
\hline \multirow{6}{*}{$\mathrm{La}$} & La-50-1 & 31.10 & \multirow{2}{*}{36.16} & Mode I \\
\hline & La-50-2 & 41.40 & & Mode I \\
\hline & La-70-1 & 61.35 & \multirow{2}{*}{60.63} & Mode I \\
\hline & La-70-2 & 60.40 & & Mode I \\
\hline & La-120-1 & I & \multirow{2}{*}{135.5} & Mode II \\
\hline & La-120-2 & I & & Mode II \\
\hline \multirow{6}{*}{$\mathrm{Lb}$} & Lb-50-1 & 59.16 & \multirow{2}{*}{41.6} & Mode I \\
\hline & Lb-50-2 & 42.65 & & Mode I \\
\hline & Lb-80-1 & 58.26 & \multirow{2}{*}{57.5} & Mode I \\
\hline & Lb-80-2 & 50.13 & & Mode I \\
\hline & Lb-120-1 & I & \multirow{2}{*}{108.68} & Mode II \\
\hline & Lb-120-2 & I & & Mode II \\
\hline \multirow{6}{*}{$\mathrm{Lc}$} & Lc-50-1 & 44.39 & \multirow{2}{*}{36.7} & Mode I \\
\hline & Lc-50-2 & 46.00 & & Mode I \\
\hline & Lc-70-1 & 56.65 & \multirow{2}{*}{65.43} & Mode I \\
\hline & Lc-70-2 & 56.13 & & Mode I \\
\hline & Lc-120-1 & I & \multirow{2}{*}{141.44} & Mode II \\
\hline & Lc-120-2 & I & & Mode II \\
\hline \multirow{2}{*}{$\mathrm{Ld}$} & Ld-0-1 & 39.10 & \multirow{2}{*}{43.48} & Mode I \\
\hline & Ld-0-2 & 44.90 & & Mode I \\
\hline
\end{tabular}

